A Cognitive-Process Analysis

of Taxpayer Compliance

John S. Carroll

WP-1739-85

January 1986

Prepared for the Symposium on Taxpayer Compliance Research, National Academy of Sciences, South Padre Island, Texas, January, 1986. 


\section{A COGNITIVE-PROCESS ANALYSIS OF TAXPAYER COMPLIANCE}

John S. Carroll, Sloan School of Management, M.I.T.

The purpose of this paper is to explore the usefulness of a cognitive approach to taxpayer compliance. The assumption is made that taxpayers make compliance-relevant decisions about reporting, filing, listing income, claiming deductions, and so. forth, and this decision-making metaphor can be useful as a general model of taxpayer behavior.

The federal government is supported by income taxes. About $53 \%$ of federal tax revenues comes from individual income taxes and another $11 \%$ from corporate income taxes (IRS, 1985, p. 21), Noncompliance arises in several basic ways: failure to file a return, underreporting of income (legal or illegal), overstating deductions, and refusing to pay what is owed. For 1981, the IRS estimated that noncompliance with the tax code created lost revenues of $\$ 81.5$ billion, enough to pay the national deficit for that year (IRS, 1983). Both IRS estimates and survey results of self-reported tax cheating show that noncompliance increased substantially in the late 1970 s (Kinsey, 1984). There is no question that noncompliance is a serious problem that creates financial costs and furthers a climate of disrespect, antagonism, and selfishness in the relationships between citizen and polity Recognition of this problem led to the creation of the Taxpayer Compliance panel at the National Academy of Sciences.

If we consider taxpaying behaviors to be the result of purposive decision-like cognitive processes, then theories of decision making become relevant to explaining why taxpayers comply or fail to comply with the tax 
requirements. The basic premise of decision models is that people have preferences, and choose alternatives so as to achieve preferred outcomes. I will first describe decision models based on utility maximization, beginning with concepts of economic rationality. Economists consider utility theory to be a description of individual behavior, an equilibrium toward which behavior tends in the long run. Psychologists treat utility models as a standard or prescription of rational behavior against which actual behavior is compared (e.g., papers in Rahneman et al., 1982). Considerable research has been devoted to testing utility models against actual behavior, compiling characteristic "errors" or "biases" defined in terms of the utility model, and seeking refinements of the utility model that would better describe the strategic and heuristic aspects of actual decisionmaking. In the second section I depart from positivist testing and modification of utility models and explore what goes on in the minds of taxpayers using a finer-grained cognitive approach based on an understanding of the operation and limitations of the human mind. Decision heuristics uncovered by this approach are discussed, including some new thoughts about hierarchical and inter-temporal decisionmaking. Research directions are suggested that use the cognitive approach to pose policy-relevant questions about taxpayer decisions and behaviors.

UTILITY MAXIMIZING MODELS OF DECISION MARING

\section{Expected Utility}

The standard economic model specifies that decisions maximize expected utility. The expected utility of any decision alternative is assessed by identifying the possible consequences or outcomes, assigning a desirability 
or utility to each outcome, and attaching likelihoods to uncertain outcomes. Each outcome is multiplied by its likelihood and the weighted or discounted outcomes are summed to create the expected utility of that alternative. The alternative with the most favorable expected utility is then selected and imp lemented.

Let us consider a taxpayer who is considering an illegal deduction of $\$ 100$ and judges the probability of audit to be $5 \%$. If audited, the taxpayer would have to pay the $\$ 100$ plus a penalty of $50 \%$ of the taxes owed $(\$ 50)$. If we ignore interest rates and treat the taxpayer as risk-neutral, then the expected utility analysis would involve two alternatives: (1) not taking the deduction, in which case the result is some current wealth state $W$, and (2) taking the deduction, which can result in two outcomes - $-\mathrm{plus} \$ 100$ if the taxpayer is not audited, and $W$ minus $\$ 50$ if the taxpayer is audited. The expected utility of being honest is simply $U(W)$, and the expected utility of cheating is . $95[U(W+100)]+.05[U(W-50)]$. For the risk-neutral taxpayer, we can assume that $U(W)=0$ and $U(W+X)=X$ for convenience, and the result is that the expected utility of being honest is 0 , compared to 92.5 for cheating. The taxpayer therefore cheats.

The expected utility formulation allows for risk attitudes to be represented in the shape of the utility function. A concave shape implies risk aversion (actually, the concave shape confounds risk-aversion and diminishing marginal return for money, Schoemaker, 1982). A risk-averse person would refuse a fair bet such as a coin toss for $\$ 1$, because the added utility of the extra dollar is smaller in magnitude than the subtracted utility of losing. A convex shape represents risk-seeking, and such a person would take the bet because the possible added utility is greater than the equally-possible subtracted utility. It is possible to generate an 
extremely risk-averse utility. function that would lead the potential tax cheat above to comply, even though he or she has only a $5 \%$ chance of being audited and faces a relatively small loss.

The same kind of analysis has applied the normative economic model to criminal behavior (e.g., Becker, 1968). Failure to comply with the tax laws can be considered as a form of criminal behavior. Criminal behavior, and property crimes in particular, have been viewed by many social scientists as a rational act resulting when individuals evaluate the expected utility of both criminal and noncriminal activities, and then choose the alternative with the highest net payoff. Thus, if the gains of tax cheating or any form of criminal behavior outweight the risks, then people should cheat on their taxes or commit the appropriate crime. This viewpoint suggests that tax cheating could be deterred by increasing the risks involved (e.g., more surveillance, harsher penalties, e.g., Blumstein, 1983). Extending the Utility Model

The same analysis is able to accomodate other, nonmonetary consequences associated with each alternative. For example, being honest may carry positive self-evaluations (pride) or negative self-evaluations (feeling like a sap, regret), whereas cheating may make a person feel competent and stimulated if they succeed, or guilty and anxious if they are caught. Other consequences such as the regard of friends, reputation, going to jail, losing one's job, and becoming a tax consultant can be accomodated by assigning them a utility (either a monetary equivalent or a satisfaction score). The consequences do not even have to involve self-interest: there could be positive utility assigned to the use of one's money by the government to provide services, or to the moral impact of a "tax revolt" on wasteful government spending (cf. Sears \& Citrin, 1985). In such a way all 
consequences are made measurable and commensurable, without changing the underlying logic of calculating expected utility. A more complicated analysis considers that these outcomes may be different in kind, requiring a multiattribute utility (Reeney \& Raiffa, 1976). Instead of a single utility dimension, there is instead a utility space permitting more complex tradeoffs and interactions among types of utility.

Utility analyses can also be extended like a decision tree to consider sequences of probabilistic outcomes. For example, a sophisticated taxpayer might consider the likelihood of being audited, and the consequences of an audit might be partially certain (e.g., having to gather records and write letters) and partially risky (will the IRS disallow a deduction?). If the IRS disallows a deduction, several outcomes are possible (pay it back, pay it plus fine, pay it plus large fine, pay it plus go to jail). If more severe penalties are experienced, there are possible additional consequences such as public disapproval, loss of friends, loss of business income or job. Additional choices may reside on branches of this tree, such as the options available if one is audited and fined (pay the fine, appeal, conceal it from friends, leave town, etc.). The complete assessment of these complex scenarios would be quite difficult, and it is not surprising that such analyses are often the province of professionals called decision analysts who aid decision makers to structure decision problems and work through to a conclusion. It is interesting to note that decision analysts consider their contribution to be the process of structuring and restructuring a problem rather than the computational aspects of calculating an "answer" (Keeney \& Raiffa, 1976).

\section{Utility-Like Models}

Formal utility theories offer axiomatic mathematical justification for 
their structure. However, many other models have been developed that have some of the same components or structure as the formal models, but lack the axiomatic basis. These are considered as useful descriptive models of decision making. We will discuss two families of these utility-like theories: expectancy theories and policy-capturing.

Expectancy theories propose, as does utility theory, that people seek desired outcomes and weight these outcomes by their likelihood. For example, the Theory of Reasoned Action (Ajzen \& Fishbein, 1980) proposes that behavior is determined by intentions to enact that behavior which arise from two components: attitude and norms. Attitude toward the behavior is computed in utility-like fashion as the product of the likelihood that the behavior will produce a conseqence multiplied by the favorability of the consequence, summed over all relevant consequences. Norms are also computed in utility-like fashion as the product of the likelihood that salient referent others or groups think you should enact the behavior multiplied by the motivation to comply with their wishes, summed over all relevant referent others. Relevant consequences and salient referent others are elicited from groups of respondents using consensus and common sense as criteria for identification. Although the particular mechanics of the questions and formulae are different from formal utility theory, the net result is to propose that people choose behaviors that maximize a combination of expected personal and interpersonal consequences.

There are many varieties of expectancy theories (see Feather, 1982; Porter \& Lawler, 1968; Vroom, 1964) that direct attention to many of the same variables and have similar multiplicative form. They propose that people are motivated to perform behaviors that are expected to lead to desirable consequences. There is no doubt that such theories are good predictors of 
behavior, and that people do generally seek favorable consequences.

Policy-capturing models of decision making predict decisions from linear combinations of input cues or judgmental dimensions, often using multiple regression as an analytic procedure for revealing the functional relationships between cues and decisions (Hammond et al, 1975; Slovic \& Lichtenstein, 1971). The weights associated with dimensions, whether empirically-derived or directly elicited, are considered to represent the relative importances of the dimensions, or the decision-maker's "policy." The "dimensions" of policy-capturing models are abstractions or correlates of the "consequences" of utility theories. For example, in choosing a tax preparer, policy-capturing models could include cues such as quality of firm, reputation, and training, which serve as proxies for the consequences of amount of tax to pay and risk of various penalties.

Whereas formal utility theories begin with the multiplicative model specified by theory, policy-capturing studies usually begin with a simpler linear model and typically find that more complex terms (configural judgments) offer little extra explanatory power. Thus, returning to our example of a person considering cheating on his tax return, the policy-capturing approach might first try a model treating penalty and likelihood of audit as separate dimensions that are weighted and added. An additional cross-product term would be tested to see if it helped explain judgments or decisions. In this fashion, studies of the evaluation of crime opportunities in terms of dimensions of probability and consequences find additive relationships rather than the multiplicative terms required in utility theory (Carroll, 1978, 1982).

In considering these various models, the real issue is the extent to which a particular model is correct in its details and whether any 
discrepancies matter. This depends on what the model is being used for: is it meant to predict aggregate behavior or individual behavior, or correspond to the process by which individuals make decisions? Paramorphic models (Hoffman, 1960) are good predictors but do not reproduce the process or mechanisms by which the behavior came about. Various combinations of so many intuitively reasonable predictors are bound to correlate with behavior, particularly when cues are positively correlated with each other (cf. Dawes \& Corrigan, 1974, on strength of linear mode1). Rather specific and data-intensive tests may be necessary to distinguish among models (e.g., experiments and functional measurement, Anderson, 1981). For example, determining whether the combination of probabilities and consequences is additive or multiplicative might require either lots of wel1-controlled data or careful study of the domain where the probability of a consequence reached zero. A model that predicts everyone cheats a little more when the economy is worse may predict aggregate tax revenues as well as a model that explains the outcomes as an increase in specific categories of tax cheaters, but these models have different policy implications.

\section{Policy Implications}

If taxpayers are maximizing utility, then the way to ensure compliance is to make the expected utility of reporting and paying appropriate taxes higher than the expected utility of various forms of noncompliance. The deterrence hypothesis does this by increasing the costs of noncompliance through surveillance and penalties. For example, Blumstein (1983) argues that the penalties for overstating deductions or failing to report income are far too low. If taxpayers perceive a $5 \%$ chance of discovery, then discovery should carry a penalty twenty times the taxes saved to deter a risk-neutral tax cheat. Other unpleasant consequences could be added on to the discovery 
process, such as public disclosure, seizure of property, nasty audit examiners, or whatever. Of course, the risk is a full-blown war between tax cheats, sympathizers, and the government (Joint Committee on Taxation, 1983, p. 47). More audits, withholding, and reporting requirements, and "Big Brother" data files that crosscheck taxpayers with reports of income sources, charities, utility companies, and so forth seem necessary to increase the risk of detection. However, such tactics may only create a larger underground economy and less visible ways to cheat (Ragan, 1985). There are extreme structural changes that would greatly curtail the opportunity for tax cheating: Making tips or barter non-taxable, eliminating deductions, going to an all plastic economy (no cash) with central reporting of all transactions, and so forth.

It is also possible to make tax cheating less beneficial (lower the tax rates) or to make compliance less costly (simpler forms) and more beneficial (growing numbers of people feel they are not getting good value for their tax money, Rinsey, 1984, p. 4).

If we turn our attention to multiattribute utility theories that identify non-monetary outcomes (e.g., Ajzen \& Fishbein, 1980), the question becomes, "What outcomes are taxpayers seeking or avoiding by complying or not complying?" It appears, for example, that concepts of fairness are important to taxpayers and that the tax laws do not jibe with common ideas of fairness. The same failure to list a cash transaction could be motivated by greed, a belief that one's taxes are too high, a comparison to others who do not report such transactions, redress for the imposition of the tax laws, or simple laziness.

Behaviora1 Decision Theory

Utility theory posits a high degree of rationality. Taxpayers and tax cheaters are expected to gather information relevant to risks and benefits, 
and combine this information in a systematic way (e.g., weight the desirability of outcomes by their probabilities of occurrence and add).

This view of rationality and human behavior has been challenged in the past several decades by researchers who believe human rationality is severely limited. Beginning with Simon $(1945,1955,1957)$, a field of study has developed primarily within psychology that examines human behavior as intendedly rational but limited in attention, memory, and computational capability. This information processing or cognitive school examines the ways in which human cognitive functions are limited, the mechanisms for achieving adequate performance within these limits, and the consequences for behavior.

March and Simon (1958), March (1978), Fischhoff et al.(1983) and others have identified assumptions underlying economic utility theories that seem to require overly rational behavior. First, economists assume that preferences change slowly relative to incentives. However, decision researchers have suggested that preferences may be very unstable (Fischhoff et al., 1980), may be the result of decisions rather than their cause (Festinger, 1957; Weick, 1977), or may stabilize only after considerable experience (Schein, 1978). Second, utility theory assumes that all alternatives are considered, evaluated, and compared so that the best can be chosen. However, beginning with the satisficing rule proposed by Simon (1955), behavioral decision theorists have suggested that only a limited set of alternatives are considered, that search may stop when a satisfactory alternative is found, and that information about each alternative may be evaluated by rules other than expected utility such as comparison against criteria or some other noncompensatory strategy (Einhorn, 1970; Montgomery, 1983; Tversky, 1969). Third, numerous researchers have remarked on the difficulty people have in dealing with probabilities (Tversky \& Rahneman, 1974). Although the concept 
of weighting outcomes by probabilities seems clear in utility theory, the way people actually respond to probability does not seem to follow the calculus of probability (Rahneman and Tversky, 1979; Einhorn \& Hogarth, 1985).

The rapidly developing literature known as Behavioral Decision Theory is replete with empirical demonstrations that people violate the assumptions of economic utility theory (for reviews see, e.g., Slovic et al, 1977; Rahneman et al, 1982; Hogarth, 1980). For example, there are simple gamble-pairs that can be constructed in which one gamble offers a high probability of winning a small amount and the other offers a low probability of winning a large amount. When asked to bid to play each gamble once, people typically bid more for the one with a large potential gain. However, when asked to choose which they would play if they could only play one, they choose the one where they are most likely to win. Such a discontinuity between choices and bids is inconsistent with any normative rationality. These errors persist when people are rewarded with money for good performance (Grether \& Plott, 1979) or whan actual gamblers in Las Vegas casinos play the same gambles on roulette wheels for real money (Lichtenstein \& Slovic, 1973).

A particularly detailed and applicable use of Behavioral Decision Theory was a study of the failure to buy federally-subsidized flood insurance (Runreuther, et al, 1978). According to utility principles, this insurance was offered at highly favorable rates, assuming that residents had accurate risk and cost data and combined them to maximize utility. However, a national survey of flood-prone areas revealed that residents assessed their risks and costs differently from the experts. Some of these differences arose from judgmental biases discussed later. However, even considering residents' own assessments, those who bought insurance and those who did not exhibited similar distributions of expected utility. Instead, it appeared 
that residents' purchasing decisions depended on informal decision rules such as whether neighbors and relatives bought insurance, what their insurance agent said, and whether they could tolerate another thing to worry over. Rather than summarize the Behavioral Decision Theory literature, I will review research on a specifically-relevant domain showing that criminal behavior is governed by mental processes somewhat different from utility mode 18.

\section{Behavioral Research on Criminal Decision Making}

Conceptually, we may divide the decision process of a potential criminal into intelligence (information gathering) and choice (use of rules to turn information into a decision). Several studies have given potential criminals the information presumed necessary for evaluating a crime opportunity, and examined the choice rule that was followed. Research that manipulated the amount of gain, likelihood of gain, severity of punishment, and likelihood of punishment in hypothetical crime situations found that subjects are sensitive to these variables but do not combine them into the interaction terms (representing expected risks and payoffs) necessary for computing expected utility (reviewed in Carrol1, 1982). Carroll (1978) conducted individual-level analyses and found that responses to the information was essentially additive. Many subjects focused on only one dimension and either ignored the others or made minor adjustments based on one or two other dimensions. Only $41 \%$ of subjects were responsive to the likelihood of capture; $60 \%$ to the likelihood of success; $67 \%$ to the penalty; and $84 \%$ to the available money. These data suggest very strong "dimensional preferences" (Slovic \& Lichtenstein, 1968) and a tremendous difficulty combining multiple pieces of relevant information into a single judgment. These results are quite consistent with the decision behavior in other domains such as clinical 
psychology and medicine, where experienced decision makers exhibit considerable inconsistency, dissensus, and use of simple additive rules rather than the complex configural rules that they claim to use (e.g., Camerer, 1980; Goldberg, 1970; Johnson et al., 1982).

Other research suggests that potential criminals not only fail to use a rational choice rule, but also fail to gather appropriate information. The Assembly Committee on Criminal Procedure (1975) studied knowledge of criminal penalties and concluded, "It appears that knowledge of penalties can not act as deterrents since these are unknown until after a person has committed a crime or become a prisoner" (p. 78). Paternoster et al. (1982) report a panel study showing that behavior more strongly determines perceptions of risk than perceptions influence behavior. Research on taxpayers also shows various misconceptions, including overassessments of the likelihood of audit, and misconceptions about the role of the IRS in tax law creation (Aitken \& Bonneville, 1980; ICF, 1985).

The above studies suggest that potential criminals (and people in genera1) are very deficient in their ability to evaluate alternative courses of action. However, other criminological research suggests that experienced criminals have a great deal of technical and interpersonal skill and knowledge relevant to specific crime opportunities. Interviews with experienced criminals suggest that certainty and severity of punishment are not static properties of crime, but under partial control of the criminal. Criminals are expert at controlling or minimizing risk. Thus, it makes little sense to ask the abstract question, "What is the probability that a burglar will get caught on a particular attempt?" although statistics exist to compute such a probability by estimating number of burglaries and burglars caught. It makes more sense to ask, "How do you keep from getting caught?" 
The criminal's skill in leaving no evidence that will stand up in court, in manipulating the legal system through bargains and bribes, in setting up and carrying out crimes and disposing of the gains is indicative that an experienced criminal faces different opportunities and sanctions than does and amateur (Inciardi, 1975; Letkemann, 1973). This research is consistent with studies showing that people will accept risks they consider controllable, such as driving a car, far in excess of risks they consider uncontrollable, such as environmental carcinogens (Slovic et al, 1980; Starr, 1969).

This viewpoint is, in fact, consistent with the research on expert decision making. Experts are viewed as knowing a great deal, but being unable to apply or combine that knowlege in a sufficiently systematic way. Thus, "bootstrapping" techniques have arisen for creating decision aids that utilize expert knowledge but do the combination rule in a mechanical way (Camerer, 1980; Dawes, 1971; Sawyer, 1966). Johnson (in press) has called attention to the knowledge experts have of rare events, what are called "broken leg cues." Broken leg cues are valid but appear very infrequently, and therefore are difficult to elicit from experts or to detect in a regression study with samples of decisions. However, they are an advantage experts have over models of more typical cases.

Carroll (1982) has suggested that research showing that people consider only one or a few pieces of information at a time and research showing that criminal behavior seems responsive to complex and multiple factors can be reconciled by allowing the decision process to be extended over time in such a way that features are sequentially incorporated into decisions and behavior. Thus, the criminal uses considerable judgment and knowledge in evaluating a particular opportunity, but at any one moment is only making 
limited use of simple information.

For example, one of Letkemann's (1973) interviewees remarked: "When I was down to a certain level I would go out" ( $p .22)$. Lack of money was one factor initiating a search for a good opportunity. Another interviewee provided a sequential ordering of decision factors:

Usually, the assessment of economic value precedes the assessment of risk. A safecracker may, while on legitimate business, spot a particularly "easy" safe. He may then assess the probable economic value of the safe's contents. Whether the value is high or low, if the risks are low, he may "make" the safe. On the other hand, if both are high, he may also attempt the job. (p. 151)

This simple contingent process model (Payne, 1973) can be interpreted as:

(1) assess money in pocket (if high, no crime; if low, go to step 2);

(2) assess certainty of success (if low, no crime; if high, go to step 3);

(3) assess amount of gain (if low, go to step 4; if high, go to step 5);

(4) assess risk (if high, no crime; if low, go to step 5);

(5) commit crime -- a process with substeps involving the planning and execution of the crime. In comparison with utility theories, the above decision process is not optimal because it lacks thorough consideration of alternatives and information, and formal combination of information into an assessment of each alternative. However, the process is certainly responsive to the environment and possibly highly effective. Johnson and Payne (in press) suggest that simple heuristic rules can approximate the decision quality of the utility rule at a lower "cost" in time and effort.

Clarke and Cornish (in press) and Weaver and Carroll (in press) have suggested that criminal decision making can further be separated into at least two kinds or levels of decisions: a decision to enter (or leave) the role of criminal, which refers to a decision to be open and aware of certain 
events and opportunities, and decisions about specific opportunities. This corresponds to strategic vs. tactical, or career vs. job choices. For example, in a study of expert and novice shoplifters, Weaver and Carroll found that experts make very rapid considerations of specific shoplifting opportunities, and focus on tactical choices for avoiding detection and acquiring an item, but do not consider distal consequences such as jail or social embarassment. Novices take twice as long considering an item and seem to both reason out tactical choices from scratch and consider more fundamental issues of the moral, legal, and social consequences of shoplifting and getting caught. This suggests that experienced shoplifters not only know more about tactics, but also have made a prior "standing decision" (cf. Cook, 1981) or "standard operating procedure" (Cyert \& March, 1963) that established their willingness to shoplift when suitable opportunities are found. Those opportunities are then assessed on different (partially overlapping) characteristics from the prior decision. An interesting question that we will discuss later is what shifts the decision process from tactical decisions back to reevaluating the standing decision. Prospect Theory

Prospect Theory (Tversky \& Rahneman, 1979) is intended to account for certain empirical phenomena in risky decision making, typically involving simple gambles. These phenomena appear to violate the utility-maximizing model. Errors and biases have accumulated over the years such as the Allais Paradox, certainty effects, a confusing empirical literature on risk preferences, and preference reversals induced by trivial shifts in wording (Hershey et al, 1982; Hershey and Schoemaker, 1985; Hogarth, 1980). Prospect Theory postulates mathematical choice processes that can account for many of these phenomena in a parsimonious way. 
Prospect Theory retains the structure of utility theory by including a utility-like valuing function, a probability-like weighting function, and the multiplicative computational rule. However, several changes are introduced into the evaluation phase of utility theory in order to account for the results of empirical research on decisions: (1) value is calculated relative to a reference point rather than total wealth position, allowing the separation of "gains" from "losses"; (2) the shape of the value function varies with each individual, but the "modal" value curve is concave in the region of gains and therefore risk-averse, but convex for losses and therefore risk-seeking, and the loss curve is steeper than the gain curve; and (3) probabilities are replaced by a decision weight curve that is discontinuous in shifting from certainty to risk (producing a "Certainty Effect") and shallow for low probabilities (resulting in the probability of an event and its complement summing to less than 1.0 ). Some of the phenomena utility theory associates with risk attitudes are explained in the value function, but others are explained in the decision weights.

The revised evaluation phase in Prospect Theory is only part of its contribution to the theory of decision making. Before prospects are evaluated, there is an earlier phase called editing or framing which defines the domain of alternatives, the outcomes of each alternative, and sets a reference point. It is in this editing phase that real-world decisions are transformed into prospects (gamble-like abstractions) and later evaluated prior to choice.

The implications of Prospect Theory for taxpayer compliance are many. The basic message is that changes in the objective costs and benefits of compliance may have erratic impact on taxpayers because of the editing and 
evaluation processes. For example, there is a discontinuity in the decision weight function between certainty and small probabilities, implying that there is a fuzzy point at which risk shifts from "no chance" to "risky" and then is weighted more heavily than objectively warranted. Once this point is reached, increases in probability have less impact than one would expect. However, changes in high probabilities have much larger impact on preferences than proportional changes in low probabilities. Since the exact location of the discontinuity is unspecified, it is difficult to base policy on its existence. If the probability of penalty were doubled, and taxpayers were made aware of this, it might have no impact if they believed the probability was very small anyway (twice nothing is nothing), might have some impact but not twice the effect if the probabilities were in the shallow part of the curve, might have moderate impact if the probabilities were in the steep part of the curve, and might have very large impact if the change shifts people from certainty (of no risk) to uncertainty.

This situation is made more complex by the editing operation. The same objective situation can be framed in many different ways. A person who takes an illegal deduction may face a $1 \%$ chance of being fined in a given year, but over a 37-year period the same person faces about a $50 \%$ chance of at least one fine. Slovic et al (1978) found that reframing the probability of a serious auto accident from per-trip to per-lifetime increased favorability toward seatbelts and predictions of own use.

The editing operation also affects how probabilities are combined. The $1 \%$ chance of a fine may reflect a $2 \%$ chance of an audit and a $50 \%$ chance of a fine if audited. The evaluation of this two-stage probability is not equivalent to the evaluation of the product $(p=1 \%)$. Tversky and 
Rahneman (1981) found that people tend to respond to the second stage probability more strongly than the first stage, suggesting that it may be possible to get more impact for the same policy by advertising a highly-probable conditional probability rather than a low-probability event. Or, the auditing sample itself could be reframed as an intensive audit of randomly selected counties such that the probability of being audited given that your county is selected is much higher. Similarly, Slovic et al. (1976) found that subjects evaluate the probability of a chain of events by the overall coherence of the chain and the highly likely conditional events can compensate for the unlikely ones. This leads to the paradoxical result that longer conditional chains may be rated more likely than shorter (also Tversky \& Rahneman, 1982b).

The proposition that outcomes are evaluated against a reference point, coupled with the changes in the value functions as outcomes change from gains to losses, has considerable power for explaining the impact of contextual information on preferences. For example, doctors confronted with a hypothetical epidemic that would kill 600 people if unchecked prefer a program that will "save" 400 lives to a program that has a one-third chance of saving no lives and a two-thirds chance of saving all 600 lives. However, they prefer a program with a one-third chance that 600 will die and a two-thirds chance that no one will die to a program where 200 will die. The difference in the choices is that in the "saving" lives version, the reference point is set as if the 600 had died and the saving of 400 lives is a gain from that reference point, but in the second version the reference point is set with no one dead yet and 200 deaths represent a loss.

Someone who has paid $\$ 7000$ in taxes and owes another $\$ 100$ at the end 
of the year could frame his situation as a $\$ 100$ loss, a $\$ 7100$ loss, a $\$ 200$ gain over last year when he owed $\$ 300$ at the end of the year, a $\$ 500$ gain over last year when he paid $\$ 7600$ in taxes, or almost any gain or loss if he takes as a reference point what his neighbor or his coworker or "people like him" are paying. Since people find losses very aversive, we might expect that someone would strive harder to reduce a "loss" than to make an equivalent "gain," even though the distinction may depend on a reference point that seems arbitrary to us.

Loftus (1985) proposed that withholding has the effect of shifting the reference point and, therefore, increases in withholding will decrease the motivation to reduce the taxes owed at filing time (by legal or illegal means). This seems reasonable if the reference point is indeed zero taxes owed on April 15 and if the reference point on salaries and other withheld income sources also shifts to the new reduced levels (which may not be reduced but simply less increased from last year than otherwise). The theoretical principles for how people bundle gains and losses are (Thaler, 1983): (1) a series of small gains is preferred to one large gain, (2) one large loss is preferred to a series of small losses, (3) it is better to offset a small loss against a larger gain, and (4) it is better to keep separate a small gain and a larger loss. Although we know that people will try very hard to reduce losses, we do not know how they frame changes in tax requirements over time. Increased withholding on salaries or dividends or tips could be perceived as a series of small losses. In such a case, Prospect Theory proposes that it is better to bundle small losses together into one large loss to reduce the impact (as we do in using credit cards). However, increased withholding could be perceived as a small loss bundled together with a larger gain (salary or salary 
increases), which would make it preferred to the end-of-year large loss.

Although Prospect Theory has considered the importance of the editing phase and has studied several potent framing effects, there is as yet no theory of how the editing processes work. In a general way, "frames" can be thought of as viewpoints or metaphors that help structure ill-structured problems, thus separating figure from ground, highlighting some aspects of a situation and hiding others (Russo \& Schoemaker, 1985). For example, do taxpayers frame their tax behavior as "compliance" or "avoidance" (Scholz, 1985)? If compliance, then the taxpayer may have strategies for identifying legal obligations and fulfilling them. If avoidance, then the taxpayer may have strategies for identifying loopholes and scams. These seem to imply fundamentally different behaviors. As a second example, Reaganomics seems to have framed taxes as an indication of government waste, a loss to the individual taxpayer and to the society (ie., less spending). They have increased the sense of unfairness and failure to get value from tax money, as indexed by opinion polls about attitudes toward taxes (ICF, 1985). On the other hand, it is possible to frame taxes as a contribution and sharing. In this way, the "frame" serves both to make salient certain benefits or costs of taxpaying and establish a reference point of what government services are worth, what "should" be paid, or what is "fair."

Prospect Theory, as well as the utility theories previously discussed, requires people to judge the probabilities and outcomes attendant on various alternatives. Utility theory considers probabilities and dollar equivalents to be constituents or primitives of the decision process. Even studies attempting to disprove utility theory typically supply probabilities and dollar outcomes. They thus turn uncertain decisions 
into risky decisions (Einhorn \& Hogarth,.1985; Lopes, 1983) and shortcut the process of assessing probabilities and outcomes. This simplification has been very useful for disproving the economic utility model since, presumably, human performance would deteriorate even further in more ambiguous and complex contexts. However, if our goal is to understand and model actual decisions rather than to disprove the utility model, we must recognize that such changes and simplifications in problems can have serious impact on results (Hershey et al., 1982; Payne, 1982). Changes in the way information is presented (e.g., graphs vs. numbers), the order of presentation, the context or wording of questions, all have been shown to affect decisions. In the next section we discuss the way people assess probability and outcomes using judgmental heuristics.

\section{Judgmental Heuristics}

Judgments of probability have in some ways had a parallel history to the study of decision making. In the beginning were formal mathematical models, in this case Bayes " Theorem for updating probabilities (Edwards, 1954) and the entire probability calculus. Evidence began accumulating that people did not follow Bayes' Theorem (Slovic \& Lichtenstein, 1971). A major breakthrough occurred in a series of papers by Rahneman and Tversky in the early 1970s, summarized in Tversky and Rahneman (1974). They suggested that people have fundamentally different understanding of probability than the accepted mathematical models.

Research shows the dominance of the particular, the personal, and the comparative over the general, the impersonal, and the absolute. For example, in judging the likelihood of being penalized for cheating on taxes, most people would not consider statistical information about the number of people penalized in a given year to be as compelling as specific 
instances (Rahneman \& Tversky, 1972; Nisbett \& Ross, 1980), especially events that happened to the self or a known other (Tyler, 1980). Likelihood would be evaluated by recalling or imagining (and sometimes seeking out) instances of the event. The ease with which such instances can be brought to mind, known as availability (Tversky \& Rahneman, 1973), determines the subjective sense of likelihood or confidence in future occurrence. Although the availability heuristic is often useful for estimating likelihood, and usually gives good results, it tends to favor events that are easily imaginable or recallable. For example, a recent well-publicized plane crash creates widespread concern for airline safety, which gradually abates as the salience of the event decreases over time. Similarly, a well-publicized conviction for tax fraud should make the likelihood of punishment temporarily increase, and the same event can be made more salient with pictures, and connections to taxpayers such as the same city or other similarities; the IRS seems to save some juicy examples for late March to create this effect on taxpayers.

However, not all information that is available is considered relevant or even used in an expected way. The representativeness heuristic (Rahneman \& Tversky, 1972) describes a process by which information is matched up for similarity with proposed hypotheses or understandings of the causes of events. Thus, one coworker who relates how she never reports tips and has never been audited could outweigh a news story about IRS prosecutions of major tax cheats or a news story about stepped-up auditing activities. The reason is that the coworker is highly.similar and the one case is considered very compelling in comparison to stories about people whose lives and noncompliance activities are different from our own, or abstract information about probability in general. In fact, 
stories of the prosecution of major tax cheats may have paradoxical efects similar to the "gambler's fallacy" -- the small tax cheat feels safer knowing the IRS is busy with other types of problems. Many items of information could be viewed as indications of danger from some perspectives and safety from others. Runreuther (1976) found that many people in flood-prone areas dropped their flood insurance after a flood, apparently from the belief that since a "once-in-ten-years" flood had just happened, they were now "safe". If the person believes that auditing resources are fixed (like the supply of floods), then every revealed case decreases his personal risk. If the person is assessing auditing probabilities, then every revealed case increases his personal risk!

Thus, people are seeking an underlying structure to information, but it is a structure of commonsensical meaning and causality rather than the acausal categorization of events in formal probability theory. This distinction is most clearly seen in the difference between causal and diagnostic information (Tversky \& Rahneman, 1980, 1982a). Although they are equally informative in a statistical sense, people reason with causal information far more readily than with diagnostic information. For example, they understand that a tall father is very likely to have a tall son, but are less willing to predict that a tall son is likely to have a tall father. Statistical information that fits a causal hypothesis is readily used: a particular automobile accident is more likely to involve a Green cab than a Blue $c a b$ because Green cabs have a higher accident rate (interpretable as Green cabs having worse drivers). But statistical information that is equally informative yet lacks a causal interpretation is not used: the same accident is not judged more likely to involye a Green cab simply because Green cabs are more numerous. 
The fact that information is interpreted in terms of prior understandings is well exemplified by the tendency to confirm or support hypotheses. People tend to selectively attend, recall, and interpret information in such a way as to support their own views. For example, Lord et a1. (1979) found that people given one research study that supported their views on capital punishment and one that supported the opposite position became even more convinced of their own position and interpreted the contrary study as being methodologically weak. If one gives credence to supporting evidence and disparages opposing evidence, it is always possible to become more convinced of one's own correctness. Thus, people not only rationalize the morality of their own conduct (Sykes and Matza, 1967), but also rationalize the evidence about likely consequences and even about past consequences (dissonance reduction, Festinger, 1957). A classic example in the domain of public risk is that the Three Mile Island nuclear reactor accident convinced anti-nuclear people that reactors were a terrible danger because so many unanticipated events could trigger a near-disaster; yet pro-nuclear people were convinced by the same event that reactors were safe because the safety systems really did work under a severe test (Slovic et al, 1980). This is not to imply that people cannot learn or revise their opinion, but only to say that people do not give up their supposed knowledge easily. One of the most powerful and pervasive psychological tendencies is to reason comparatively rather than absolutely. Prospect Theory draws upon this tendency, and so does the anchoring and adjustment heuristic. This heuristic suggests that we estimate unknown quantities, whether likelihood or outcome, by adopting an anchor and using our knowledge about the current situation to adjust the anchor. Unfortunately, we find that the 
revision process is usually incomplete and the adjustment is not sufficient -- estimates remain too close to the anchor. The fact that confidence limits are usually too narrow is explicable as the provision of an estimate range by adjustment from the best guess (Lichtenstein et al., 1982). The phenomenon that choices among gambles may be inconsistent with bids can be interpreted as anchoring and adjustment. Specifically, choice is based on overall evaluation and comparison of the gambles, but bids apparently create an anchor on the possible monetary winnings, which are then adjusted or discounted (insufficiently) for likelihood and risk (Lichtenstein \& Slovic, 1971, 1973).

Einhorn and Hogarth (1985) proposed that the assessment of frequency evidence to estimate a probability is based on a combination of anchoring and adjustment and imagination or availability. They suggest that estimates of probability are anchored on the proportion of evidence and arguments supporting a hypothesis, and then adjusted for the amount of evidence, alternative hypotheses and evidence that can be imagined. On the basis of a few simple assumptions, their evidence model predicts a relationship between strength of evidence and probability that, under certain conditions, is very similar to Prospect Theory's decision weight function. Their theory implies that attitudes toward uncertainty (or ambiguity in their terminology), in addition to risk attitudes, affect preferences. For example, hypothetical businessmen were more likely to insure against a low-probability loss when there was uncertainty about the probability of loss, but less likely to insure against a high-probability loss when there was uncertainty (Study 4). Thus, preferences among alternatives depended on risk and uncertainty in complex ways. In the context of tax compliance, an illegal deduction with a low 
probability of detection would be increasingly avoided if there was less certainty about the likelihood of detection, perhaps counteracting the risk-seeking tendencies in Prospect Theory. However, a deduction with a higher probability of detection might be more sought after under uncertainty, thus augmenting risk-seeking. Without research directed at the specific parameters of the Einhorn and Hogarth model, such predictions can only by stated as if...then hypotheses.

Anchoring and adjustment principles can also be seen in decision making on the larger scale. Lindblom's (1959) statement of "incrementalism" and March and Simon's (1958) "problemistic search" both refer to the tendency to base decisions on past decisions with small revisions. Budget decisions are typically based on past budgets; Jimmy Carter's attempt to introduce "zero-based" budgeting points out the enormous effort involved in starting from scratch. Presumably, taxpayers follow routines and use as a model their last-year's tax forms or a. friend's tax forms in order to avoid starting from scratch. The problem, of course, is that change is slow and responses to changes in the tax laws or one's personal situation may be absent or insufficient (cf. Scholz, 1985).

\section{Comments on Utility Models}

Utility models have taken us a long way toward understanding decision processes because they are simple, broadly applicable, mathematically-tractable, and sensible for theory and application. They also fit human behavior and market behavior in useful.ways. However, several decades of research demonstrate that utility models are wrong in almost every detail. Even Nobel-Prize Economists are willing to speak out against the model (Arrow, 1982). Research and theory has benefitted by having a benchmark or comparison (or straw man), and new models drawing on 
the structure of utility theory but incorporating psychological principles are revolutionizing the field because they combine the scope and power of utility models with stronger empirical support (e.g., Prospect Theory). Considerable progress is also being made by assuming that deviations from utility models represent ways to optimize decision quality and decision costs, a meta-utility (Beach \& Mitche11, 1978; Payne, 1982; Johnson \& Payne, in press).

However, there is a compelling alternative approach to the study of decision making that avoids starting from utility models. Essentially, the utility models postulate simple algebraic rules for evaluating or selecting alternatives given certain classes of information. They are basically input-output models that use utility models to predict whatever goes on in the "black box" of the human mind, and thus define away the necessity of studying mediating mental processes. The alternative is to put aside the axioms and optimizing rules, and ask the more inductive psychological question, "How do people make decisions?" Considerable progress has been made addressing this question from a cognitive approach, and it is to this theory and research that we now turn.

\section{THE COGNITIVE APPROACH TO DECISION MARING}

The cognitive approach considers the human mind as an information processing system. Interest centers on those mechanisms and processes by which the mind takes in information, transforms it, and constructs a response. In contrast to behaviorists who traditionally sought to interrelate responses directly to stimuli, and preferred to summarize the entire mental apparatus in terms of "prior learning history," the 
cognitivists hypothesize a detailed set of mental mechanisms that, in principle, could reference detectable physiological events and structures. The make-up of the human mind is typically conceived as a set of sensory transducers that produce an initial input, an attention mechanism that serves as a gateway to further processing, a series of memories that store sensory input and transformed inputs for greater and lesser periods of time, and a central processing unit or working memory that operates on information. Many cognitive psychologists use the metaphor of the computer as a way to understand the mind and computer programs as a way to express theories of mental processes.

\section{Limited Rationality}

The fundamental principle underlying this analysis of the mind is the concept of limited rationality, or physical limits on the various processes that comprise thinking (e.g., Newell \& Simon, 1972). Thus, attention, memory, computational capacity, and so forth are all limited. In order to function in a complex world, people must create simplified views of that world, and simple strategies for responding to our approximations or educated guesses. This is usually quite adequate, but can be shown in particular circumstances to be a very poor representation of reality.

Information processing researchers sometimes adopt the same strategy as those following the "psychophysical paradigm" (Phillips, 1983) by assuming a correct answer and examining deviations from correctness. However, the goal is not a cataloguing of errors and biases but an identification of situations in which useful descriptive information can be found. Discrepancies suggest the presence of intuitive strategies and other limited processes. Descriptive models can then be developed that 
mimic the way people behave. In this way, researchers can identify fundamental and generalizable processes at an intensive level of detail. [Suggestions can even be made for improving performance in real-world situations. However, the transition from demonstrations of errors and biases to real-world applications is tenuous because additional mechanisms may exist in natural settings (e.g., learning, Hogarth, 1981; organizations, Cyert \& March, 1963)].

\section{Process-Level Descriptions}

The hallmark of the cognitive approach is the attempt to describe in detail the characteristics of mental apparatus (e.g., the size of short-term memory) and the step-by-step processes by which tasks are performed. At the extreme, highly stylized laboratory tasks allow the study of elementary information processes (Posner and McCleod, 1982). For example, the task of scanning a list to find a particular character would enable the testing of models of attention, memory, and similarity judgments. More complex but well-structured tasks such as mental arithmetic and chess have sucessfully been analyzed into component acts (Simon, 1978). Detailed comparisons of human behavior with computer programs have allowed the development of basic knowledge about attention, memory, and problem-solving strategies.

The same goals and style are evident in the cognitive approach to more complex but ill-structured tasks (Simon, 1973). These tasks are characterized by having no obvious way to break up and process the elements of the task. Instead, each person essentially recreates their own version of the task and solves it in their own way. General principles can be adduced, and theories can be built in considerable detail, but behavior cannot be reduced to the atomic level of elementary information processes. 
In the past decade, the cognitive approach has become a major conceptual and methodological viewpoint in fields that are considerably less structured and bounded than the original domain of research. Cognitive approaches to social psychology, medicine, criminal justice, and so forth seem to offer rigor and precision for these fuzzier domains. The themes characterizing this approach include the selection or construction of bounded tasks with apparent cognitive content, careful research designs or controls on the tasks, observations intended to suggest process-level detail, and step-by-step mechanistic models.

The methods of the cognitive approach generally involve individuals engaged in a definable task, an extension of the laboratory origins of the field. The desired level of theoretical detail requires observations capable of revealing such detail. There are two basic strategies to make observations extremely informative: 1) to structure the task so carefully that performance implies specific mechanisms, and 2) to look for products and indicators of the separate processes under observation.

The cognitive approach has mostly been limited to brief repetitious tasks requiring an answer, and subjects who are presumed to want to get the right answer. It has mostly ignored how people acquire the knowledge, skills, and motives they bring to the tasks, long-term effects of behavior, or social conventions and relationships. It has only begun to think about how the tasks chosen for study relate to the more complex and interwoven tasks in the "real world." In short, the approach presumes basic inherent processes of the human mind with interchangeable domain-specific content from a particular task. Accordingly, it should be evident that I am presenting the cognitive approach not as "the answer" to 
the study of decision making, but as a valuable and insightful line of theory and research that also has its limitations.

Decision Heuristics

Schwab et al (1979) conclude their review of studies of expectancy-value models with the comment that, "there is a nagging suspicion that expectancy theory overintellectualizes the cognitive processes people go through when choosing alternative actions" (p. 146). Highly simplified decision rules, such as satisficing (choose the first alternative that is good enough), habit, or modelling of others ' behavior seem to be more frequent than the systematic intellectual activity assumed in utility theories. In this section, we will review studies emerging from the cognitive approach that seek to identify decision making behaviors rather than presume or test the utility model.

Behavioral research has proposed or discovered a variety of decision rules or heuristics. The guiding assumption is that people have a repertoire (Relley, 1973; Payne, 1976) of such procedures, some of them widely shared, some more specific to individuals or to particular tasks. A currently active area of research and theorizing is to study the conditions under which different decision strategies are used (Payne, 1982). Some of this research suggests that strategy. choice is itself a utility-maximizing choice balancing effort and other decision costs against the quality of the decision outcomes (ie., decision strategies differ in their likelihood of selecting the best alternative) (Beach and Mitche11, 1978). Other research seems to suggest that people learn through trial and error or select through a less sophisticated process a strategy that is easy enough and good enough in the particular situation (Payne, 1982; Johnson and Payne, in press). 
Rather than enumerate the variety of decision rules uncovered to date (see, e.g., Svenson, 1979), it seems more reasonable to discuss the dimensions on which these rules vary. First, some rules are organized around alternatives while others are organized around attributes. For example, utility-like models process the information about each alternative and produce a score for that alternative; the highest-scoring alternative is then chosen. In a contrasting example, the Elimination-By-Aspects rule (Tversky, 1969) sorts all alternatives on the most important attribute or dimension, and holds for further consideration only those alternatives scoring highest. Ties are broken by considering the next most important attribute, until only the best alternative (or alternatives if more than one are to be chosen) is left. A particular alternative never gets a summary "score" that can be generalized beyond the choice set. The addition of a new alternative affects the ordering in ways that depend on the particular alternatives in the choice set.

Second, some decision strategies are compensatory, in that unfavorable information can be counteracted by other highly favorable information, but other strategies are noncompensatory. Utility models and additive policy-capturing models allow attributes to compensate or average. A low probability of being penalized for cheating on taxes could be compensated by a huge penalty for the few people that are caught (cf. Blumstein, 1983). In contrast, a satisficing or conjuctive rule requires that certain key attributes be above criteria or threshholds. Any attribute that falls below criterion cannot be compensated by other attributes that are highly favorable. For example, those taxpayers with a strong code of honesty might not "trade-off" honesty against monetary gain: it is enough to know that tax cheating is dishonest. 
Third, strategies differ in the extent to which they are task specific or generalizable. Payne (1973) describes the task of choosing among risky gambles as a contingent process model in which the gambles are first classified as "good- or "bad" gambles based on the probability of winning compared to the probability of losing, and then the amount to win and lose are processed comparatively in different ways depending on the initial classification. It seems likely that people have an endless capacity to create task structures and task-specific decision procedures (Humphreys and Berkeley, 1983; Phillips, 1983) -- to instantiate decision strategies in new ways, to combine familiar routines, and to create new procedures. It is therefore not surprising that individual differences in decision strategies are quite substantial, and that strategies change in response to "seemingly minor changes in tasks" (Einhorn \& Hogarth, 1981, p. 61). Research investigating these decision procedures has uncovered characteristics of tasks that shift decision makers from strategy to strategy. When faced with more alternatives, decision makers tend to use noncompensatory strategies that quickly reduce the magnitude of the task (Payne, 1976; Payne and Braunstein, 1978). Phased decision rules seem quite common, in which multiple alternatives are screened by a noncompensatory rule until only two or three are left, which are then compared by a more effortful but more powerful compensatory strategy. Other features of the decision task such as number of attributes, time pressure, response mode, information display format are reviewed in Payne (1982).

However, substantial individual differences in strategy use have been found. Weaver and Carroll (in press) studied the decision making of expert and novice shoplifters as they walked through retail stores. Novices seem to be deterred by any undesirable attribute, a conjunctive 
rule, whereas experts balanced deterrents with facilitators or discounted the deterrents in the face of additional information, a compensatory rule. Experts seem to develop appropriate task-specific rules (Johnson, in press; many others) but may have difficulty stepping up a level to consider the usefulness of their rules, as in studies of creativity that show a failure to innovate by those too experienced in a domain (Hogarth, 1980).

It is important to realize that the cognitive approach has revealed these decision strategies not simply by measuring output judgments as a function of input task attributes and situations, but also by developing new methods for observing the hypothesized mental processes comprising these strategies (Carrol1, 1980; Payne et al, 1978; Svenson, 1979). Process-tracing techniques such as the monitoring of information search, collection of verbal protocols, and measurement of response time offer new insight into mental mechanisms. For example, the difference between strategies organized by alternative and strategies organized by attribute can be physically revealed in information search studies where decision makers scan information in dramatically different ways depending on which strategy they are using. Verbal protocols, statements made during the task, and output judgments as a function of input conditions reinforce the information search data to make a strong case for the process by which people decide.

\section{Hierarchical Decision Making}

The fact that there are multiple ways to come to a decision suggests a hierarchical process: a strategy must be "chosen," which then "chooses" the alternative to be enacted. This could create an infinite regress: how do we choose a strategy to choose a strategy to... Humphreys and Berkeley (1983) and Jaques $(1976,1978$ ) suggest several levels of decision problem representations, each setting the conditions under which the next level 
operates. Expertise, abstract analytical ability, cognitive complexity, cognitive style (e.g., Rilmann \& Mitroff, 1976) and other traits and experiences could be considered to reference both the extensiveness of options at any level, and the number of levels that can be deliberately traversed (ie. a "high level" person can deliberately question a fundamental assumption that alters the strategies for selecting decision procedures).

Such a hierarchical structure, in which prior decisions or acceptance of procedures or premises serve to structure further decisionmaking, has the advantage of efficiency in that the full range of issues need not be confronted at once, but this very partitioning of decisions reduces the resultant decision quality, because higher-level structures tend not to change (March \& Simon, 1958; Cyert \& March, 1963; Lindblom, 1959). The concept of a "frame" in Prospect Theory (Tversky \& Rahneman, 1981) similarly expresses the simplification of a problem by the selection (consciously or unconsciously) of a particular set of definitions and viewpoints. Our discussion of criminal behavior suggests that the decision to be a criminal precedes or sets the boundaries around decisions to commit specific crimes. In discussing decision strategies, we can talk about choosing not to decide (Corbin, 1980), deciding to experiment in order to learn how to decide (Einhorn, 1980; Hogarth, 1981), and so forth, which reflect this movement across levels. In organizations, standard operating procedures (March \& Simon, 1958; Cyert \& March, 1963) have the effect of efficiently handling common situations with the attendant cost of not recognizing or responding we 11 to new situations.

Applying these ideas to income tax compliance requires that we consider compliance to involve a series of decisions and a set of strategies that may differ among taxpayers and across situations. The simple act of basing your 
tax return on your neighbor's could reflect either low-level or high-level processing. It would be very low-level if the person copies the various elements of the neighbor's tax return, substituting only where amounts differ. It would be somewhat higher-level if the taxpayer imitates the neighbor's rules and procedures rather than his products. It could be even higher-level if the taxpayer imbeds the imitation routine in another routine, such as "follow his rules on those parts of the form that are similar to mine and follow other rules on different parts of the form, or under different circumstances."

Operating at a high level implies laying out a tax plan, including recording and reporting information, setting withholding, finding tax relief opportunities, remaining aware of changes in the tax laws, and so forth. Once the planning is accomplished, tax behavior consists mostly of following the plan, e.g., putting records safely away, opening an IRA, and so forth. Later behaviors, such as computing deductions, are constrained by all the earlier tax-relevant behavior. Of course, a tax plan, no matter how detailed, does not guarantee the diligence necessary to follow it (Scholz, 1985). Once the habit of not recording business expenses emerges, very different routines have to be engineered to create the tax reporting figures out of a "shoebox" of receipts (or, worse yet, no shoebox of receipts). Operating at a low level implies very little planfulness, or following the same plan every year, and a mad scurrying near April 15 to assemble and interpret tax materials. For simple situations this may be sufficient, but for others. it may mean carrying scraps of paper to a tax preparer to be magically turned into a return, or estimating various figures to reach a "reasonable" or "fair" result.

Taxpayers undoubtedly differ in how "top-down" or rationalistic, planful, 
and proactive their tax compliance decisions are. They may switch back and forth between self-aware and deliberate decision making and the habitual, unthoughtful carrying out of procedures set down earlier in the process. For most people, "popping up" a level and considering premises as problematic is unusual. Most taxpayers simply hire a third-party preparer to operate for them at higher levels; I wonder how the client conceptualizes the acts of the preparer.

The above analysis presumes that at the highest level the taxpayer has established a frame or problem statement of "How do I pay my taxes?" or "How do I comply with the tax laws?" However, it is possible to reframe the entire problem as "How can I pay the least taxes"? or "Where can I cheat?" or even as "How can I pay my fair share?" These questions involve motivation or moral reasoning (Rohlberg, 1976), referring to the relationship between citizen and government as one based on fear, personal gain, norms, rationality, or morality (Rinsey, 1985; Vogel, 1974). We could view this as a problem of conformity (Cialdini, 1986) or organizational socialization (Van Maanen \& Schein, 1979).

Surveys of taxpayers reveal several attitudinal types that could be interpreted in terms of a basic motive or frame: (1) Honest Taxpayers, (2) Utility Maximizers, (3) Beaten Taxpayers, (4) Equity Seekers, and (5) Need Mobilized (freely translated from terms used by Yankelovich et al, 1984). It is interesting to consider what might generate a transition from one type to another (cf. Scholz, 1985). For example, how many examples of unfairness and frustrating interactions with tax forms are necessary to turn Honest Taxpayers into Equity Seekers? How much need will mobilize a Beaten Taxpayer? How much rational debate on taxpaying does it take to turn everyone into Utility Maximizers? 
Even when the taxpayer frames the problem as cheating rather than compliance, this cheating can also be done in a planful, high-level way, or a reactive, low-level way. An auto mechanic could have made a "standing decision" to look for ways to avoid paying taxes owed. Reasons for making such a decision could include personal need, a sense of frustration with his economic progress, a sense of inequity when considering rich people or publicity about rich people who pay very little taxes, the pronouncements of the government decrying waste of (his) tax money, contact with friends or other mechanics who regularly cheat, a desire to get whatever he can, a need to feel superior, and so forth. Given such a decision to avoid paying taxes where possible, the more planful, top-down strategies call for assessing overall amounts or percentages to hide, types of transactions to avoid recording, and other goals and rules. A less planful mode is simply to look out for good opportunities, such as customers who pay in cash and have frequent transactions so they are known to be "safe" and are unlikely to be keeping track (cf. Kagan, 1985). This "now-and-then" behavior may be guided by elaborate rules or by something closer to "impulse buying" -- the occasion arises, the thought of cheating occurs, and the situation passes a few simple criteria of risk. An even less planful mode is to come to the end of the year with a few shoeboxes full of records and some bills to pay. Several "trial balances" may be attempted and a strategy constructed at that time for balancing safety and need, or for meeting a target tax amount.

The factors that produce a decision to be open to noncompliance may therefore differ from the factors that effect a particular decision to cheat or a particular tactical choice. Even if we consider tax behavior to occur only during tax season, then the decision to cheat could be made once and later actions predicated on a currently-unquestioned prior premise that the 
person is "open" to such opportunities.

I envision the context of taxpaying to be similar to the "garbage can" model (Cohen, March, and 01sen, 1972) in that there are taxpayers looking for relief, IRS publications providing information, third-party preparers offering advice, tax shelters and other "solutions" looking for "problems" they can solve, media reporting of a broad variety of tax-relevant information, tax consultants trying to design new strategies, and many different kinds of taxpayers circulating in the "garbage can" affecting one another in various ways. Although the "garbage can" may seem like just a visual metaphor, it has been found useful in analyzing organizational decisions (March and 01sen, 1976) and presents a description of preferences as emerging from a discovery process that includes acting and experiencing outcomes (March, 1978; Weick, 1977). My personal garbage can of mail in the past few months includes a solicitation to buy a book called How te Beat the IRS (secrets of a former IRS agent), the opportunity to subscribe to the Iax Avoidance Digest and get the free gifts such as "Tax Secrets Worth a Fortune" and "27 Major Loopholes in the Tax Laws," and a request for a contribution to the National Taxpayers Union promising to fight for changes in the federal pension plan supported by our taxes!

The concept of hierarchical strategies suggests that change occurs at the lower levels more readily than at higher levels, and that change typically involves modifications or additions to existing behavior rather than major shifts. Change occurs because of the continual press of events and opportunities in the "garbage can" but the taxpayer has to be prepared to change and capable of exercising the new behaviors. The stimuli to change are manifold: changes in the tax laws that force changes in tax strategies, acute financial need that makes the year-end "bottom 1 ine" unacceptable, the 
financial gymnastics of a tax preparer, accidents and errors that bring no negative consequences, friends ${ }^{-}$revelations of their own tax strategies and outcomes, repeated media disclosure of legal and illegal tax avoidance tactics, growing feelins of inequity, frustration with tax forms, or simply the propensity to explore when some slack is available. It seems clear that we have created a societal climate that prevents stability for many taxpayers. Frequent changes in the tax laws, the economic incentives to innovators who create legal tax avoidance strategies, the publicity given to corporations and the wealthy who strive to reduce their taxes, the public debate over the fairness and effectiveness of taxes, negative feelings toward government encouraged by the Reagan administration, the societal emphasis on personal well-being and deemphasis of communal motives, and so forth, all push in the direction of thinking about taxpaying more, making the taxpaying process more costly and frustrating, and defining one's behavior as "tax avoidance."

\section{Competence of Taxpayers}

Any analysis of taxpayer compliance and noncompliance would have to consider decisions as the confluence of three factors: opportunity, skills, and motivation. Opportunity and skill combine in two ways. First, deliberate tax cheating occurs when skill is sufficiently high to take advantage of opportunities to cheat. The taxpayer has to become aware of an opportunity and then select or develop a strategy to use the opportunity. Naturally, such actions require a certain motivation to carry out these behaviors in the face of costs such as time, effort, and anxiety over risks. Second, accidental tax cheating occurs when skill is sufficiently low that errors are made.

The IRS analysis of audit research presumes that noncompliance has two 
components: tax cheating that produces undercompliance, and errors that result in random under- and overcompliance. Thus, results showing $38 \%$ of taxpayers with underpayment errors and $8 \%$ with overpayment errors is interpreted as $30 \%$ net undercompliance (ie., $30 \%$ cheat, and $16 \%$ make errors that cancel out) (IRS, 1983; Rinsey, 1984). However, errors are likely to be omissions, and omissions of income that produce undercompliance are likely to far outweigh omissions of deductions that produce overcompliance. Intensive IRS audits find that $17 \%$ of taxpayers fail to list income sources of $\$ 50$ or less (Kinsey, 1984).

Opportunity, skills, and motivation are all influenced by the complexity of the behaviors required to comply with the tax codes. For example, the Form 1040 instructions are written at an average 10 th grade readability, beyond the capabilities of at least $25 \%$ of adults (Comptroller General, 1978). I recently attempted to complete a Series 5500 form for Reogh Accounts that was new for 1984. I was unable to figure it out without help from an accountant, and further discovered an error in the form that would have produced a nonsensical final result had I followed the instructions word for word.

Such complexity has a direct effect on accidental tax cheating, by making the forms too difficult to fill out accurately. It also makes tax compliance a social situation, by forcing large numbers of taxpayers to seek some sort of assistance from the IRS, family and friends, or tax preparers. Further, it creates more opportunities for tax cheating because there are so many different "niches" and so many gray areas where the laws are vague or the only accessible traces of transactions are by personal report. More of these "niches" are available to more skilled taxpayers or those who have access to such skills through knowledgeable friends or paid tax advisors. 
Further, and possibly most important, the complexity of tax forms has major motivational impact. First, it creates frustration and thereby generates efforts to get around the requirements or get back at the IRS. Second, it creates feelings of inequity as those experiencing more difficulty realize that others can pay for arcane expertise and profit from the complexity. Third, it offers a challenge to some taxpayers who would like. to beat the system. Finally, the complexity changes the perceived risks associated with noncompliance. Taxpayers may believe the system is so cumbersome that they are less likely to be caught, or recognize that it is so complex that everyone will be making errors. Long (1981) emphasizes that "it is difficult to speak of a "correct' return" and that an instructor at an IRS school for training revenue agents told her that "agents could find 'errors" in 99.9 percent of all tax returns, if they wanted to" (p. 205). But, this complexity blurs the line between legitimate (albeit aggressive) tax avoidance and tax evasion, making the IRS hesistate to label anyone as a deliberate tax cheat and apply heavy penalties. Presumably, many tax evaders realize that they can claim to have made an error or to have been. confused, and merely have to pay the taxes they would have paid in any case.

Steps to simplify tax forms and tax requirements would thus have many benefits. More people could do their own returns and feel better about the process. The sense of equity would be enhanced. The opportunities for cheating would be reduced, particularly those available to the more wealthy. The risks associated with noncompliance might be seen more clearly and administered more closely. The costs of administering the tax code would greatly decrease. However, there are constitutencies that benefit from complexity (the IRS, Long, 1981; and paid tax preparers) and reasons to believe that complexity increases uncertainty and therefore reduces 
noncompliance (Popkin, 1985; at least sometimes, Einhorn \& Hogarth, 1985).

The simplification and clarification of tax forms requires an understanding of how people think about and process their taxes. It is more than just a question of reading level. Instructions should follow the natural categories and the temporal and hierarchical organization of taxpayers' behavior. There may need to be several forms for different levels of sophistication.

\section{RESEARCH DIRECTIONS}

The history of deterrence efforts is not highly encouraging. Many apparently successful deterrence strategies had only temporary effects. People adapt; they revise probabilities back down with experience, reframe for themselves, adopt new avoidance strategies, and so forth. This is the history of attempts to deter shoplifting (Bickman et al, 1979), drunk drivers (Ross, 1982), and family violence (Tanchen \& Witte, 1985). Before large-scale changes or influence attempts are recommended, we need a better model of taxpayer behavior that can predict long-term as well as short-term. effects and that is general enough to be informative across changes in the tax laws.

The current research efforts using intensive audits and public opinion polls are helpful but incomplete. Besides the possibility of bias, these strategies have not provided much detail about taxpaying behavior. I believe issues of "How much?" have dominated over issues of "What?" and "How?" and "Why?" We need a much better understanding of the many varieties of taxpaying behavior. Once we understand how competence, motivation, and opportunities play out over time into strategies and changes in behavior, we 
would be better able to deal with issues of prevalence and the effectiveness of possible interventions. I have organized the discussion of research directions around methods: surveys, tests, process-tracing, longitudinal studies, and field quasiexperiments.

\section{Surveys}

Survey research and focus groups, the sort of research that has already been done (ICF, 1985; Yankelovich et al., 1984), can reveal considerable information about taxpayer behavior and strategies if the right questions are asked. Questions about noncompliance have generally lumped together many kinds of noncompliance. Questions have not been addresses at overall strategies or what generates reevaluation of strategies. Careful and intensive survey work should be done focused on the following questions:

1. What series of events occurs during the year relevant to taxes?

2. What strategies do you use to collect information, keep records, report information, reduce your taxes, and prepare to pay your taxes?

3. When is the last time you changed the way you report, pay, or compute your taxes? What did you change and why?

4. Can you think of other ways to do your taxes? Can you think of ways to avoid paying taxes, including ways that are illegal and sure to get you in trouble? For each of these tax avoiding strategies, explain how you heard of it or thought it up, how much you think you could save, what the risks are and how likely they are, and why you aren't doing them.

5. What are you doing now to reduce your taxes? Continue as in Q. 4.

6. Suppose I could guarantee you that you would not be audited next year no matter what you put on your tax forms. What would you do 


\section{differently?}

7. This year the IRS is going to audit some income tax forms on a random basis. However, in exchange for agreeing to be audited, you can have a $\$ 50$ tax rebate. Would you be willing to do this? What is the smallest rebate you would accept in exchange for being audited? Suppose your return was to be placed in a pool with a $50 \%$ chance of being audited. What is the smallest rebate you would accept in exchange for being placed in that pool?

8. What exactly happens when you are audited? What is the worst thing that could happen, and the best? How would your family, friends, and employers feel if they knew you were audited? How would they feel if they knew you had to pay a penalty for failure to report all your income?

The first use of such surveys should be to identify concepts and issues such as types of strategies and types of taxpayers. It would be entirely appropriate to focus attention on groups that are considered "high risk" such as part-time contractors, owners of cash businesses, and so forth (Witte, 1985). However, given the danger that previous methods may not have revealed all the market niches for noncompliance, it may be desirable at an early stage to do some sampling for heterogeneity. The second use of surveys is to identify the prevalence (and therefore the impact and potential savings) of various tax strategies, noncompliance activities, and taxpayer types. This is a critical policy step but should not be pushed ahead of our understanding of taxpaying itself.

\section{Competency Test}

A second mode of data collection would be a tax competency test, aimed not at motivation but at ability. Some of the above questions address what 
people know about tax strategies. The tax competency test would begin with some factual questions about the law, what taxes are used for, the penalties for noncompliance, and the likelihood of these penalties. A second part would ask respondents to interpret tax instructions and fill out a sample form given input information. The third part would be most important. Given a complex set of information about a hypothetical person including income sources and expenses and record availability, they would be asked to fill out tax forms for that person and to design a tax strategy for them. Instructions could vary in terms of avoiding an audit, paying the minimum taxes, showing available cash at tax time to be very small or very large, and so forth. The complex cases should be designed around known problem areas such as people with a lot of cash income.

Such a test could be administered to samples of taxpayers of various types, and to tax preparers. Although people are unlikely to admit that they use illegal or questionable tax strategies, the purpose of this test is to distinguish two issues: what people believe they should do in the sense of preparing a tax return in the manner desired by the IRS (and their competency to know what to do and carry it out), and what people know how to do but are afraid to imply as their own practice. In order to elicit the latter knowledge, the test has to be presented under some conditions as a challenge and hypothetical instance (e.g., what would an unscrupulous tax preparer do?) with no implications for their own tax behavior.

\section{Process-Tracing}

The aim of the process-tracing approach is to focus as closely as possible on cognitive processes involved in tax behavior. Although survey research can also address these questions, it is thought that people have limited ability to report retrospectively on their cognitive processes. Process-tracing methods are designed to supplement self-reports by getting 
"closer" to the mental events. Process-tracing studies would be a labor-intensive but detailed way to identify taxpaying behaviors. This hopefully would give better information about issues such as the following:

1. What is the temporal patterning of tax-relevant behaviors and decisions among various types of taxpayers?

2. Why do people decide to cheat on their taxes? When does this occur?

3. What causes people to "pop up" a level and consider their standing decision to be honest or to cheat? How frequent or rare is this?

4. What sort of strategies and plans do people use? What distinguishes more planful people from more impulsive decision makers?

5. What causes people to shift from more planful to more impulsive strategies or the reverse?

6. What are the sources of innovation in taxpaying and tax avoiding strategies? What circumstances produce innovation, and at what level does it tend to occur? What sort of people tend to be "lead users" and how are these innovations transmitted?

One good possibility is to collect verbal protocols from taxpayers. This would involve asking taxpayers to do their tax work under the watchful eye of a researcher, and to "think aloud" while doing their taxes (Payne et al, 1978). If sufficient cooperation could be obtained (money and guarantees of anonymity), the study could involve their own tax returns. Ideally, it would include not only the few hours when they fill out the forms, but also other times during the year when substantial tax planning or tax work occurs. This would require either training to self-administer the protocol procedure (perhaps backed up by taperecorded instructions), or the continual availability of a researcher to show up on short notice and observe some taxpaying activities, or agreements with the taxpayer to structure such 
activities within negotiated time periods. Otherwise, the task could be hypothetical but realistic, and completed during one or more scheduled sessions.

The key to this research is the ability to get people to reveal noncompliance as well as compliance. Researchers would have to be adept at achieving rapport and some iron-clad guarantees would have to be worked out (immunity from audit?). Survey researchers have successfully elicited reports of tax cheating and other illegal behaviors (although presumably there is underreporting). Weaver and Carroll (in press) used verbal protocols with self-reported experienced shoplifters during shopping trips in retail stores, but their "experts" were really talented amateurs rather than criminals who make a living by theft. However, even a process-tracing study of good law-abiding taxpayers would be useful for better structuring our understanding of tax compliance decisions. Instructional sets could be overlaid to promote or inhibit noncompliance (Weaver and Carroll, in press).

A second useful process-tracing approach would be the monitoring of information search behavior (Payne et al, 1978). What sort of information do people actively seek, what scanning strategies do they adopt, and how much of what they know comes casually from other people or is initiated from the outside (e.g., media, tax preparers, solicitations)? This could be done in a single time period by offering a large number of information pamphlets and observing what is actually read. In a field experiment, various types of information could be sent to people who would later be tested for their understanding and use of that information. Retrospective reports of seach activity would be useful but probably incomplete, and diary reports (as suggested below) might be a reasonable way to track search behavior over extended time periods. 


\section{Longitudinal Studies}

Longitudinal studies are also needed, examining tax behavior across a year or several years (coupled with detailed cross-sectional surveys allowing comparison of new, early, middle, and late taxpayers). One relatively inexpensive procedure is a diary study, in which taxpayers are paid to keep a diary of all tax-relevant behaviors. Surveys utilizing a panel design would also be useful. The costs could be kept low by using some combination of mailed and telephone questionnaires after initial personal interviews.

\section{Field Tests of Interventions}

Based on the conceptual work and results of surveys and other methods, it would be possible to field test specific interventions. Manipulations of new tax forms, instructions, information on penalties and probabilities, information about fairness, and, so forth could be tested in much the same way that marketers "test market" their advertisements and new products. Even deterrence could be test marketed by identifying a subgroup and convincing them that their returns had particular probabilities of being audited, and that they faced particular penalties. Quasiexperimental studies are also possible in the form of time-series data on various tax behaviors as changes occureed in the tax laws, audit practices, enforcement standards, and so forth. I was particularly struck by hints of a "Bicentennial Effect" with a drop in noncompliance in 1976, possibly caused by a (temporary) resurgence of collective consciousness (Rinsey, 1984). It may be that one-time quasiexperiments would be useful, especially if coupled with more carefully-designed dependent measures such as the intensive surveys and process-tracing studies already mentioned.

\section{Conclusions}

The major thrust of the suggested research is to further our basic 
understanding of taxpayer behavior, and to focus particularly on the way taxpayers think about decisions relevant to tax compliance. Underlying this approach is the assumption that attempts to deter noncompliance without understanding the sources and processes of noncompliance are unlikely to provide a satisfactory answer to the problem. Policymakers themselves tend to choose strategies that are readily at hand, such as increasing IRS audits and increasing penalties. However, we can choose from a much broader array of interventions such as public information and education, new tax forms, tax simplification, various forms of contact with the IRS, and so on.

We must also recognize that the situation is dynamic: tax laws change, avoidance strategies arise from innovators, people adapt to fear-provoking communication, economic conditions change, monitoring technologies change, the economy changes from cash to electronic exchanges, people feel better or worse about government, and so forth. We need research that will enable us to understand taxpayers well enough to anticipate or incorporate some of these changes, and that probably means a research precess that itself is adaptive.

The benefits to society include increased revenue, decreased costs of tax administration, and a shift in the numbers of people who "frame" their relationship to government in antagonistic vs. communal terms. It is not desirable for a tax system to make criminals out of so many people that it has to continually monitor, frighten, and punish them. It would be better if people saw the value in paying their taxes, and that taxpaying behavior was simple and clear. 
Aitken, S. S. and Bonneville, L.

1980 A General Taxpayer Opinion Survey. Washington, DC: CSR Inc., March.

Ajzen, I. and Fishbein, $M$.

1980 Onderstanding Attitudes and Predicting Social Behavior.

Englewood Cliffs, NJ: Prentice-Hall.

Anderson, N. H.

1981 Foundations of Information Integration Theory. New York:

Academic Press, 1981.

Arrow, $\mathbf{R}$.

1982 Risk perception in Psychology and Economics. Economic

Inquiry $20: 1-9$.

Assembly Committee on Criminal Procedure (California)

1975 Public knowledge of criminal penalties: In R. L. Henshel

and R. A. Silverman, eds., Perception in Criminology. New York: Columbia U.

Beach, L. R. and Mitche11, T. R.

1978 A contingency model for the selection of decision

strategies. Academy of Management Review 3:439-449.

Becker, G.

1968 Crime and punishment: An economic approach. Journal of

Political Economy $76: 169-217$.

Bickman, L., Rosenbaum, D., Baumer, T., Rude1, M., Christenholz, C., Knight, S, and Perkowitz, W.

1979 Phase I Assessment of Shoplifting and Employee Theft

Program: Final Report -- Programs and Strategies. Report 
to the National Institute of Law Enforcement and Criminal

Justice, Law Enforcement Assistance Administration,

Department of Justice.

Blumstein, A.

1983 Models for structuring taxpayer compliance. Pp. 159-172 in

P. Sawicki, ed., Income Iax Compliance: A Report of the APA

Section of Taxation. Invitational Conference on Income Tax

Compliance. Washington, DC: American Bar Association.

Camerer, C.

1980 General conditions for the success of bootstrapping models.

Organizational Behavior and Buman Performance $27: 411-422$.

Carrol1, J.S.

1978 A psychological approach to deterrence: The evaluation of crime opportunities. Journal of Personality and Social

Psychology 36:1512-1520.

1980 Analyzing decision behavior: The Magician's audience. Pp.

69-76 in T. S. Wallsten, ed., Cognitive Processes in Choice

and Decision Behavier. Hillsdale, NJ: Erlbaum.

1982 Committing a crime: The offender's decision. Pp. 49-67 in V.

J. Ronecni and E. B. Ebbesen, eds., The Criminal Justice

System: A Social-Psychological Analysis. San Francisco: W.

H. Freeman.

Cialdini, R.

1986 Social Motivations to Comply: Norms. Values, and

Principles. Paper prepared for the Panel on Taxpayer

Compliance, National Academy of Sciences.

Clarke, R. V. and Cornish, D. B. 
in press Modelling offenders' decisions: A framework for research and policy. In M. Tonry and N. Morris, eds., Crime and Justice: An Annual Review of Research, Do1.6. Chicago: O. Chicago.

Cohen, M. D., March, J. G., and 01sen, J. P.

1972 A garbage can model of organizational choice. Administrative

Science Quarterly $17: 1-25$.

Comptroller General

1978 Further Simplification of Income Tax Forms and Instructions

is Needed and Possible. Report to the Joint Committee on

Taxation, U. S. Congress, July 5.

Cook, P. J.

1981 Research in criminal deterrence: Laying the groundwork for

the second decade. In N. Morris and M. Tonry, eds., Crime

and Justice: An Annual Review of Research. Vol, 2. Chicago:

J. Chicago.

Corbin, R.

1980 Decisions that might not get made. Pp. 47-68 in T. S.

Wallsten, ed., Cognitive Processes in Choice and Decision

Behavior. Hillsdale, NJ: Erlbaum.

Cyert, R. M. and March, J. G.

1963 A Behavioral Theory of the Firm. Englewood Cliffs, NJ:

Prentice-Hall.

Dawes, R. M.

1971 A case study of graduate admissions: Application of three principles of human decision making. American Psychologist 26 : $180-188$.

Dawes, R. M. and Corrigan, B. 
Edwards, W. .

1954 The theory of decision making. Psychological Bulletin $51: 380-417$.

Einhorn, H. J.

1970 The use of nonlinear, noncompensatory models in decision making. Psychological Bulletin 73:211-230.

1980 Learning from experience. Pp. 1-20 in T. S. Wallsten, ed., Cognitive Processes in Choice and Decision Behavior.

Hillsdale, NJ: Erlbaum.

Einhorn, H. J. and Hogarth, R. M.

1981 Behavioral decision theory: Processes of judgment and choice. Annual Review of Psychology 32:53-88.

1985 Ambiguity and uncertainty in probabilistic inference.

Psychological Reviey $92: 433-461$.

Feather, N. T., ed.

1982 Expectations and Actions: Expectancy-Value Models in

Psychology. Hillsdale, NJ: Erlbaum.

Festinger, L.

1957 A Theory of Cognitive Dissonance. Stanford: Stanford U. Fischhoff, B., Goitein, B. and Shapira, Z.

1983 Subjective expected utility: A model of decision-making. Pp.

183-207 in R. W. Scholz, ed., Decision Making Under

Dncertainty. New York: North Holland.

Fischhoff, B., Slovic, P.\& Lichtenstein, S.

1980 Rnowing what you want: Measuring labile values. In $T$. 


\section{Wallsten, ed., Cognitive Processes in Choice and Decision \\ Behavior. Hillsdale, N.J.: Erlbaum.}

Goldberg, L. R.

1970 Man vs. model of man: A rationale, plus some evidence, for a method of improving on clinical inferences. Psychological Bulletin $73: 422-432$.

Grether, D. M. and Plott, C.

1979 Economic theory of choice and the preference reveral

phenomenon. American Economic Review 69:623-638.

Hammond, R. R., Stewart, T. R., Brehmer, B. and Steinmann, D. 0 .

1975 Social-judgment theory. Pp. 271-312 in M. F. Raplan and S.

Schwartz, eds., Buman Judgment and Decision Processes. New

York: Academic.

Bershey, J. C., Kunreuther, H. and Schoemaker, P. J. H.

1982 Sources of bias in assessment procedures for utility

functions. Management Science 28:936-954.

Hershey, J. C. and Schoemaker, P. J. H.

1985 Probability vs. certainty equivalence methods in utility

measurement: Are they equivalent? Management Science

$31: 1213-1231$.

Hoffman, P. J.

1960 The paramorphic representation of clinical judgment.

Psychological Bulletin $57: 116-131$.

Hogarth, R.

1980 Judgement and Choice. New York: John Wiley.

1981 Beyond discrete biases: Functional and dysfunctional aspects of judgmental heuristics. Psychological Bulletin 90:197-217. 
Humphreys, P. and Berkeley, D.

1983 Problem structuring calculi and levels of knowledge representation in decision making. Pp. 121-158 in $R$. W. Scholz, ed., Decision Making Onder Oncertainty. New York:

North Holland.

ICF Inc.

1985 Summary of Public Attitudes Survey Findings, Report to the IRS. January.

Inciardi, J. A.

1975 Careers in Crime. Chicago: Rand McNally.

Internal Revenue Service.

1983 Conference on Tax Administration Research Strategies. Office of the Assistant Commissioner (Planning, Finance and Research), Vols. I and II. Washington, DC: Internal Revenue Service.

1985 IRS Function Summaries: A Descriptive Summary of IRS

Qperations. Paper from the IRS Conference, January.

Jaques, E.

1976 A General Theory of Bureaucracy. London: Heinemann.

1978 Level of abstraction in mental activity. In E. Jaques, R. 0 . Gibson and D. J. Isaac, eds., Levels of Abstraction in Logic and Human Action. London: Heinemann.

Johnson, E. J.

in press Judgment under uncertainty: Process and performance. In $M$.

Chi et al, eds., The Nature of Expertise. Hillsdale, NJ:

Erlbaum.

Johnson, E. J. \& Payne, J. W. 
in press Effort and accuracy in choice. Management Science.

Johnson, P. E., Hassebrock; F., Duran, A. S. and Moller, J. H.

1982 Multimethod study of clinical judgment. Organizational

Behavior and Human Performance 30:201-230.

Joint Committee on Taxation (Senate Committee on Finance).

1983 Background on Federal Income Tax Compliance. Washington, DC:

Onited States Government Printing Office. June 21.

Ragan, R. A.

1985 On the Visibility of Income Tax Law Violations. Berkeley:

0. California. Unpub. ms.

Rahneman, D. A., Slovic, P. \& Tversky, A., eds.

1982 Judgment Under Oncertainty: Beuristics and Biases. New

York: Cambridge U.

Rahneman, D. and Tversky, A.

1972 Subjective probability: A judgment of representativeness.

Cognitive Psychology 3:430-454.

1979 Prospect theory: An analysis of decision under risk.

Econometrika $47: 263-291$.

Reeney, R. L. and Raiffa, H.

1976 Decision With Multiple Objectives: Preferences and Value

Tradeoffs. New York: John Wiley.

Relley, н. H.

1973 The process of causal attribution. American Psychologist

$28: 107-128$.

Kilmann, R. and Mitroff I.

1976 Qualitative versus quantitative analysis for management

science: Different forms for different psychological types. 
Interfaces $6: 17-25$.

Rinsey, $\cdot$. A.

1984 Survey Data on Tax Compliance: A Compendium and Review.

American Bar Foundation Tax Compliance Working Paper 84-1.

Chicago: American Bar Association, December.

1985 Theory and Models of Tax Evasion. American Bar Foundation

Tax Compliance Working Paper 84-2. Chicago: American Bar

Association.

Rohlberg, L.

1976

Moral stages and moralization: The cognitive-developmental

approach. In T. Lickona, ed., Koral Development and

Behavior. New York: Holt, Rinehart, and Winston.

Runreuther, $\mathrm{H}$.

1976 Limited knowledge and insurance protection. Public Policy $24: 227-261$.

Runreuther, H., Ginsberg, R., Miller, L., Sagi, P., Slovic, P., Borkan, B. and Ratz, N.

1978 Disaster Insurance Protection: Public Policy Lessons. New

York: Wiley.

Letkemann, P.

1973 Crime as Work. Englewood Cliffs, NJ: Prentice-Ha11.

Lichtenstein, S., Fischhoff, B. \& Phillips, L. D.

1982 Calibration of probabilities: The state of the art in 1980.

In D. Rahneman, P. Slovic, and A. Tversky, eds., Judgment

Under Uncertainty: Heuristics and Biases. New York:

Cambridge 0 .

Lichtenstein, S. \& Slovic, P. 
1971 Reversal of preferences between bids and choices in gambling decisions. Journal of Experimental Psychology 89:46-55.

1973 Response-induced reversals of preference in gambling: An extended replication in Las Vegas. Journal of Experimental Psychology $101: 16-20$.

Lindblom, C. E.

1959 The science of muddling through. Public Administration

Review $19: 79-88$.

Loftus, E. E.

1985 To file, perchance to cheat. Psychology Today, (Apri1): 35-39.

Long, S. B.

1981 Social control in the civil law: The case of income tax enforcement. Pp. 185-214 in H. L. Ross, ed., Law and Deviance. Beverly Hills: Sage.

Lopes, L.

1983 Some thoughts on the psychological concept of risk. Journal of Experimental Psychology: Human Perception and Performance $9: 137-144$. Lord, C., Ross, L., and Lepper, M. R.

1979 Biased assimilation and attitude polarization: The effects of prior theories on subsequently considered evidence. Journal of Personality and Social Psychology $37: 2098-2110$.

March, J. G.

1978 Bounded rationality, ambiguity, and the engineering of choice. Be11 Journal of Economics 9:587-608.

March, J. G. and 0lsen, J. P., eds. 
Universitets forlaget.

March, J. G. and Simon, H. A.

1958 Organizations. New York: Wiley.

Montgomery, H.

1983 Decision rules and the search for a dominance structure:

Towards a process model of decision making. $\mathrm{PP}_{\mathrm{P}}$ 343-369 in

P. Bumphreys, O. Svenson and A. Vari, eds., Analysing and

Aiding Decision Processes. New York: North Holland.

Newe11, A. \& Simon, H. A.

1972 Euman Problem Solving. Englewood Cliffs, NJ: Prentice-Ha11.

Nisbett, R. E. \& Ross, L.

1980 Human Inference: Strategies and Shortcomings of Social

Judement. Englewood Cliffs, NJ: Prentice-Hall.

Paternoster, R., Saltzman, L. E., Waldo, G. P., and Chiricos, T. G.

1982 Causal ordering in deterrence research: An examination of

the perceptions-behavior relationship. In J. Hagan, ed.,

Deterrence Reconsidered: Methodological Innovations. Beverly

Hills: Sage.

Payne, J. W.

1973 Alternative approaches to decision making under risk:

Moments versus risk dimensions. Psychological Bulletin

$80: 439-453$.

1976 Task complexity and contingent processing in decision

making: An information search and protocol analysis.

Organizationa1 Behavior and Human Performance 26:102-115.

1982 Contingent decision behavior. Psychological Bulletin 
$92: 382-402$.

Payne, J. W. \& Braunstein, M. L.

1978 Risky choice: An examination of information acquisition

behavior. Memory and Cognition 6:554-561.

Payne, J. W., Braunstein, M. L. and Carroll, J. S.

1978 Exploring pre-decisional behavior: An alternative approach

to decision research. Organizational Behavior and Buman

Performance $22: 17-34$.

Phillips, L. D.

1983 A theoretical perspective on heuristics and biases in probabilistic thinking. Pp. 525-543 in P. Humphreys, 0.

Svenson and A. Vari, eds., Analysing and Aiding Decision

Processes. New York: North Holland.

Popkin, W. D.

1985 Statutes and Principles: The Case of the Internal Revenue

Code. Unpub. ms. (Talk delivered at Law and Society

Association Meetings, San Diego).

Porter, L. W. and Lawler, E. E.

1968 Managerial Attitudes and Performance. Homewood, IL:

Irwin-Dorsey.

Posner, M. I. and McLeod, P.

1982 Information processing models -- In search of elementary operations. Annual Review of Psychology $33: 477-514$.

Ross, H. L.

1982 Interrupted time series studies of deterrence of drinking and driving. In J. Hagan, ed., Deterrence Reconsidered: Methodological Innovations. Beverly Hills, CA: Sage. 


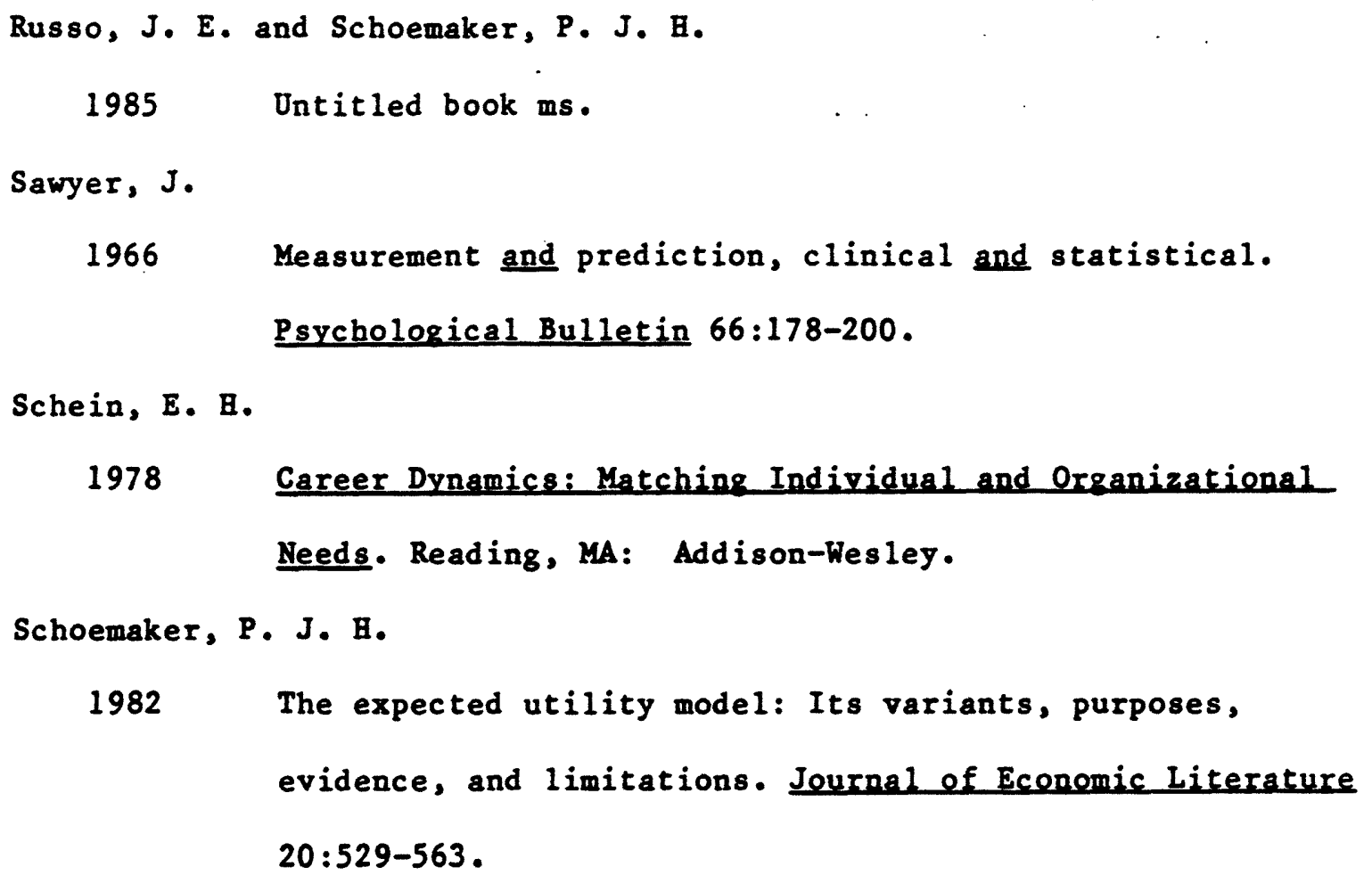

1985 Coping with complexity: A bounded rationality perspective on taxpayer compliance. Proceedings of the Seventy-Eight Annual Conference on Taxation NTA-TIA, Denver, October 13-16. Schwab, D. P., Olian-Gottlieb, J. D. and Heneman, B. G.

1979 Between-subjects expectancy theory research: A statistical review of studies predicting effort and performance. Psychological Bulletin $86: 139-147$.

Sears, D. 0 and Citrin, J.

1985 Tax Revolt. Cambridge, MA: Harvard O. Simon, H. A.

1945 Administrative Behavior. New York: The Free Press.

1955 A behavioral model of rational choice. Quarterly Journal of Economics 59:99-118.

1957 Models of Man: Social and Rational. New York, Wiley. 
Intelligence 4:101-202.

1978 Information-processing theory of human problem solving. In

W. R. Estes, ed., Handbook of Learning and Cognitive

Processes (Vol. 5). Hillsdale, NJ: Erlbaum.

Slovic, P., Fischhoff, B. and Lichtenstein, S.

1976 Cognitive processes and societal risk taking. In J. S.

Carroll and J. W. Payne, eds., Cognition and Social

Behavior. Hillsdale, N. J.: Erlbaum.

1977 Behavioral Decision Theory. Annual Review of Psychology

$28: 1-39$.

1978 Accident probabilities and seat belt usage: A psychological perspective. Accident Analysis and Prevention 10:281-285.

1980 Facts vs. fears: Onderstanding perceived risk. In R. Schwing and W. A. Albers, Jr., eds., Societal Risk Assessment: How Safe is Safe Enough? New York: Plenum.

Slovic, P.\& Lichtenstein, S.

1968 Relative importance of probabilities and payoffs in risk taking. Journal of Experimental Psychology Monograph 78 : (3, Pt. 2).

1971 Comparison of Bayesian and regression approaches to the study of information processing in judgment. Organizational Behavior and Human Performance 6:649-744.

Starr, C.

1969 Social benefit vs. technological risk. Science $165: 1232-1238$.

Svenson, 0 . 
Sykes, G. and Matza, D.

1957 Techniques of neutralization: A theory of delinquency.

American Sociological Review 22:664-670.

Tanchen, H. and Witte, A. D.

1985 Economic Models of How Audit Policies Affect Poluntary

Compliance. Paper presented ath the NTA-TIA meeting, Denver, October.

Thaler, R.

1983 Using Mental Accountine in a Theory of Consumer Behavior.

Cornell University, unpub. ms.

Tversky, A.

1969 Intransitivity of preferences. Psychological Reviex 76:

$31-48$.

Tversky, A. and Rahneman, D.

1973 Availability: A heuristic for judging frequency and probability. Cognitive Psycholegy 5:207-232.

1974 Judgment under uncertainty: Heuristics and biases. Science $185: 1124-1131$.

1980 Causal schemas in judgments under uncertainty. In M. Fishbein, ed., Progress in Social Psychology. Hillsdale, NJ: Erlbaum.

1981 The framing of decisions and the rationality of choice. Science $211: 453-458$.

1982a Evidential impact of base rates. In D. Rahneman, P. Slovic, and A. Tversky, eds., Judgment Under Uncertainty: Heuristics 
and. Biases. New York: Cambridge 0 .

1982b Judgments of and by representativeness. In D. Rahneman, P. Slovic, and A. Tversky (Eds.) Judgment Onder Uncertainty: Beuristics and Biases. New York: Cambridge 0 .

Tyler, T. R.

1980 The impact of directly and indirectly experienced events:

The origin of crime-related judgments and behavior. Journal of Personality and Social Psychology 39:13-28.

Van Maanen, J. \& Schein, E. H.

1979 Toward a theory of organizational socialization. In B. Staw, ed., Research in Organizational Behavior. Vol, 1. Greenwich, Conn.: JAI Press.

Voge1, J.

1974 Taxation and public opinion in Sweden: An interpretation of recent survey data. National Tax Journal $27: 499-513$.

Vroom, V. H.

1964 Work and Motivation. New York: John Wiley.

Weaver, F. M. \& Carroll, J. S.

1985 Crime perceptions in a natural setting by expert and novice shoplifters. Social Psychology Quarterly, in press.

Weick, R. E.

1977 Enactment processes in organizations. In B. M. Staw and G.

R. Salancik, eds., New Directions in Organizational

Behavior. Chicago: St. Clair.

Witte, A. D.

1985 The nature and extent of unrecorded activity: A survey concentrating on recent U. S. research. Unpub. ms. 
Yankelovich, Skelly and White, Inc.

1984 Taxpayer Attitudes Study: Final Report. Prepared for the

Internal Revenue Service, December. 